\title{
Effect of water stress and AM fungi on the growth performance of pea plant
}

\author{
Jaya Thakur ${ }^{1} \&$ B.P. Shinde ${ }^{2}$ \\ ${ }^{1}$ Assistant Professor, DAV College for Women, Chandigarh \\ 2 Principal , Vidya Prathisthan, Baramati, Maharashtra \\ P. G. Department of Botany, Fergusson College Pune MS India
}

\begin{abstract}
The study was conducted to determine the effect of arbuscular mycorrhizal (AM) fungi inoculation on growth of pea grown under water stressed pot culture conditions. Water stress was given to the pea plants after 30 days at the interval of 4,8 and 12 days. The data was collected at an interval of 15 days. Three replicates of each set were maintained. . The mixture of AM fungi used for current experiment included the species of Acaulospora denticulata, A. gerdemannii, Glomus macrocarpum, G. maculosum, G. fasciculatum and Scutellospora minuta. The mycorrhizal plants have shown more shoot and root length as compared to the control plants. The height of shoot and root was significantly decreased with the increase in drought stress. Mycorrhizal plants with low water stress showed enhanced shoot and root length than high water stress. The mycorrhizal plants have shown more number of leaves than control plants during drought stress. The number of leaves significantly reduced with the increase in drought stress. The leaves produced by the control plants were comparatively smaller than those of mycorrhizal plants. The dry weight of root and shoot of both control and mycorrhizal plants decreased with the increase in water stress. Mycorrhizal plants showed more dry weight of shoot and root as compared to control plants. Plants inoculated with AM fungi produce more dry weight than the control plants. The fresh weight of both control and mycorrhizal plants has been decreased with the increase in water stress interval and also the fresh weight of root and shoot was observed higher in mycorrhizal plants as compared to those of control plants.
\end{abstract}

\section{Introduction}

The term "pea" can refer to small spherical seed or to the pod. Pea is a crop of high commercial significance. Pea belongs to the Leguminosae family (Genus: Pisum, subfamily: Faboideae tribe: Fabaceae), which has an important ecological advantage because it contributes to the development of low-input farming systems by fixing atmospheric nitrogen and it serves as a break crop which further minimizes the need for external inputs. Pea (Pisum 
sativum) is an important pulse crop. Pea requires cool growing season with moderate temperature. The best suitable temperature for its germination is about $22^{\circ} \mathrm{C}$ and $13^{\circ} \mathrm{C}$ to $18^{\circ} \mathrm{C}$ for plant growth and development. Pea requires less rain and low humidity for proper growth. Pea crop can be grown in a variety of soils. A well drained soil with ample moisture retaining capacity such as deep loam soil is the best for its cultivation. Light soils like sandy loam, are suitable for early crops especially for green pod production. Heavy soils like clay loam are preferred for grain production. The $\mathrm{pH}$ range from 6 to 7.5 is the most suitable for this crop.

Mycorrhizal fungi are ubiquitous, present in all natural ecosystems in most climatic zones throughout the world. The mycorrhizal habitat probably evolved as a survival mechanism for both partners in the association, allowing each to survive in environment of low fertility, drought, disease and temperature extremes where, alone they could not. AMF are of ecological and economical important as they can improve pathogen resistance (Vigo et al., 2000; de la Pena et al., 2006) as well as biomass production (Smith et al., 2009) of the host plant. In addition, AMF mitigate different kinds of plant stresses such as drought (Michelson and Rosendahl, 1990; Auge et al., 2001; Aroca et al., 2007), or heavy metal toxicity (Hildebrandt et al., 1999) and protect plants against root herbivores (Gange, 2001). AMF helps in promoting plant growth and development by increasing nutrient acquisition and alleviating stress conditions of plants (Koide and Kabir, 2000; Koide and Mosse, 2004; Barea et al., 2005). The present study was conducted to determine the effect $A M$ fungi on the various growth parameters of pea plant during drought stress conditions.

\section{Materials and Methods}

Preparation of experimental set up

Water stress treatment was given at the Fergusson College botanical garden. In this experiment, seeds of Pea (Pisum sativum) were sown in the pots with and without mycorrhiza. Fifteen replicates of both control and mycorrhizal plants were maintained during present investigation. These plants were watered with normal water for one month at an interval of 4 days. The mixture of AM fungi used for current experiment included the species of Acaulospora denticulata, A. gerdemannii, Glomus macrocarpum, G. maculosum, $G$. fasciculatum and Scutellospora minuta. The number of AM propagules per $100 \mathrm{gm}$ soil was 260. Ten gram of mycorrhizal soil was added in the pots at the time of sowing of seeds in mycorrhizal set. The AM fungi have been shown to help in retaining moisture of soil and also help in uptake of important nutrients during stress conditions (Heikham et al., 2009). The water stress treatment was started after one month old pea seedlings at an interval of 4,8 and 12 days for next one and a half month. The different parameters studied in mycorrhizal and non-mycorrhizal plants include dry and fresh weight of root and shoot, shoot length, root length and number of leaves.

\section{Study of growth parameters}

Growth parameters were measured at the interval of 15 days from one month (30 days, 45 days and 60 days). Dry and fresh weight of root and shoot, shoot length, root length and number of leaves of mycorrhizal and non mycorrhizal plants were measured to study the comparative account of growth. 


\section{Results}

A study was conducted to determine the effect of arbuscular mycorrhizal (AM) fungi inoculation on growth of pea grown under water stressed pot culture conditions. Water stress was given to the pea plants after 30 days at the interval of 4,8 and 12 days. The data was collected at an interval of 15 days. Three replicates of each set were maintained. . The mixture of AM fungi used for current experiment included the species of Acaulospora denticulata, A. gerdemannii, Glomus macrocarpum, G. maculosum, G. fasciculatum and Scutellospora minuta.

\section{Effect of water stress and AM fungi on the dry weight of root and shoot of pea plant}

The effect of water stress on the dry weight of pea was studied with and without AM fungi at the interval of 4,8 and 12 days. The dry weight of root and shoot was recorded in control and mycorrhizal plants. The water stress was given at 4, 8 and 12 days interval in mycorrhizal as well as control plants.

Water stress has caused a decrease in the dry weight of both control and mycorrhizal plants. At the interval of 4 days, in control plants, the dry weight of shoot was $0.223 \pm 0.69 \mathrm{~g}$. But it kept on decreasing with the increase in water stress. At the interval of 8 days, it has been found to be decreased up to $0.192 \pm 0.74 \mathrm{~g}$. At the interval of 12 days, it has been decreased to $0.140 \pm 0.71 \mathrm{~g}$. However, in mycorrhizal plants, at the interval of 4 days, the dry weight of shoot was $0.256 \pm 0.08 \mathrm{~g}$, at the interval of 8 days, it was $0.230 \pm 0.33 \mathrm{~g}$ and at the interval of 12 days, dry weight was $0.187 \pm 0.15 \mathrm{~g}$.

The dry weight of root in control plants at the interval of 4 days was $0.008 \pm 0.51 \mathrm{~g}$ and it had decreased to $0.003 \pm 0.58 \mathrm{~g}$ and it declined significantly at the interval of 12 days where it had been found to be $0.001 \pm 0.51 \mathrm{~g}$. In mycorrhizal plants, the dry weight of root at the interval of 4 days was $0.013 \pm 0.12 \mathrm{~g}$, at the interval of 8 days, it was $0.009 \pm 0.85 \mathrm{~g}$ but at the end of 12 days, it was found to be $0.007 \pm 0.73 \mathrm{~g}$. The results were significant at $P \leq 0.05$ level.

Table 1. Effect of water stress and AM fungi on the dry weight of root and shoot of pea plant

Water Control (g) Mycorrhizal (g)

Stress

\begin{tabular}{lllllll}
\hline Days & 4 & 8 & 12 & 4 & 8 & 12 \\
Shoot & $0.223 \pm 0.69$ & $0.192 \pm 0.74$ & $0.140 \pm 0.71$ & $0.256 \pm 0.08$ & $0.230 \pm 0.33$ & $0.187 \pm 0.15$ \\
Root & $0.008 \pm 0.51$ & $0.003 \pm 0.58$ & $0.001 \pm 0.51$ & $0.013 \pm 0.12$ & $0.009 \pm 0.85$ & $0.007 \pm 0.73$
\end{tabular}

${ }^{*}$ Results are significant at $P \leq 0.05$ level.

Effect of water stress and AM fungi on the fresh weight of root and shoot of pea plant

Water stress has caused a decrease in the fresh weight of both control and mycorrhizal plants (Table 2). At the interval of 4 days, in control plants, the fresh weight of shoot was $1.033 \pm 0.21 \mathrm{~g}$. But it kept on decreasing with the increase in water stress. At the interval of 8 days, it has been found to be decreased up to $0.973 \pm 0.19 \mathrm{~g}$. At the interval of 12 days, it has been decreased to $0.777 \pm 0.41 \mathrm{~g}$. However, in mycorrhizal plants, at the interval of 4 days, the fresh weight of shoot was $2.50 \pm 0.93 \mathrm{~g}$, at the interval of 8 days, it was $2.155 \pm 0.63 \mathrm{~g}$ and at the interval of 12 days, fresh weight was $1.823 \pm 0.48 \mathrm{~g}$. 
The fresh weight of root in control plants at the interval of 4 days was $0.113 \pm 0.48 \mathrm{~g}$ and at the interval of 8 days, it had been found to be $0.096 \pm 0.54 \mathrm{~g}$ and it had decreased significantly at the interval of 12 days where it had been found to be $0.071 \pm 0.64 \mathrm{~g}$. In mycorrhizal plants, the fresh weight of root at the interval of 4 days was $0.231 \pm 0.37 \mathrm{~g}$, at the interval of 8 days, it was $0.219 \pm 0.58 \mathrm{~g}$ but at the end of 12 days, it was found to be $0.198 \pm 0.08$ g.

Table 2. Effect of water stress on the fresh weight of root and shoot of pea plant.

\begin{tabular}{lllllll}
\hline $\begin{array}{l}\text { Water } \\
\text { stress }\end{array}$ & \multicolumn{5}{c}{ Control $(\mathrm{g})$} & \multicolumn{3}{c}{ Mycorrhizal $(\mathrm{g})$} \\
\hline Days & 4 days & 8 days & 12 days & 4 days & 8 days & 12 days \\
Shoot & $1.033 \pm 0.21$ & $0.973 \pm 0.19$ & $0.777 \pm 0.41$ & $2.50 \pm 0.93$ & $2.155 \pm 0.63$ & $1.823 \pm 0.48$ \\
Root & $0.113 \pm 0.48$ & $0.096 \pm 0.54$ & $0.071 \pm 0.64$ & $0.231 \pm 0.37$ & $0.219 \pm 0.58$ & $0.198 \pm 0.08$
\end{tabular}

* Results differ significantly at $P \leq 0.05$ level.

The fresh and dry weight of both control and mycorrhizal plants has been decreased with the increase in water stress interval. It has been found that the mycorrhizal plants have shown more fresh and dry weight of root and shoot as compared to those of control plants. This showed that AM fungi helped the pea plants during water stress.

Effect of pea water stress and AM fungi on the shoot and root length and the number of leaves of pea plant

Water stress has a negative effect on the shoot length, root length and leaf number of pea plant. It has been found that shoot length was $20.07 \pm 0.21 \mathrm{~cm}$ at the interval of 4 days water stress. At the interval of 8 days, shoot length was reduced to $16.21 \pm 0.87 \mathrm{~cm}$. At the interval of 12 days, it was $11.01 \pm 2.11 \mathrm{~cm}$. In case of mycorrhizal plants, shoot length was $23.37 \pm 3.43 \mathrm{~cm}$ at the interval of 4 days, at the interval of 8 days, it was $19.37 \pm 2.63 \mathrm{~cm}$ and it has been decreased to $14.12 \pm 2.41 \mathrm{~cm}$ at the interval of 12 days.

In control plants, root length was $4.50 \pm 1.09 \mathrm{~cm}$ at the interval of 4 days, root length at the interval of 8 days was recorded $4.32 \pm 0.46 \mathrm{~cm}$ and has been found to decrease up to $4.1 \pm 2.39 \mathrm{~cm}$ at the interval of 12 days. In mycorrhizal plants, it was recorded $4.80 \pm 1.62 \mathrm{~cm}$ at the interval of 4 days, at the interval of 8 days, it was $4.53 \pm 2.23 \mathrm{~cm}$ and at the interval of 12 days it was reduced to $4.28 \pm 3.81 \mathrm{~cm}$.

Leaf number of control plants was $28.71 \pm 2.47$ at the interval of 4 days, $25.2 \pm 0.54$ at the interval of 8 days and has been reduced to $21.63 \pm 0.87$ at the interval of 12 days. In mycorrhizal plants, it has been found to be decreased from 35.92 \pm 2.26 (at the interval of 4 days), $31.11 \pm 2.69$ (at the interval of 8 days) and $25.71 \pm 1.89$ (at the interval of 12 days). (Table3)

Water stress has caused a decrease in the shoot length, root length and the numbers of leaves at the interval of 4, 8 and 12 days in both control and mycorrhizal pea plants, but all these growth attributes were more in mycorrhizal plants as compared to control plants. The results were significant at $\mathrm{P} \leq 0.05$ level. 
Table 3. Effect of Water Stress and AM Fungi on the Shoot and Root Length and the Number of Leaves of Pea Plant

\begin{tabular}{lllllll}
\hline Water stress & Control & \multicolumn{5}{c}{ Mycorrhizal } \\
\hline Days & 4 days & 8 days & 12 days & 4 days & 8 days & 12 days \\
$\begin{array}{l}\text { Shoot } \\
\text { length }(\mathrm{cm})\end{array}$ & $20.07 \pm 0.21$ & $16.21 \pm 0.87$ & $11.01 \pm 2.11$ & $23.37 \pm 3.43$ & $19.37 \pm 2.63$ & $14.12 \pm 2.41$ \\
$\begin{array}{l}\text { Root } \\
\text { length }(\mathrm{cm})\end{array}$ & $4.50 \pm 1.09$ & $4.32 \pm 0.46$ & $4.1 \pm 2.39$ & $4.80 \pm 1.62$ & $4.53 \pm 2.23$ & $4.28 \pm 3.81$ \\
$\begin{array}{l}\text { Leaf number } \\
28.71 \pm 2.47\end{array}$ & $25.2 \pm 0.54$ & $21.63 \pm 0.87$ & $35.92 \pm 2.26$ & $31.11 \pm 2.69$ & $25.71 \pm 1.89$
\end{tabular}

* Results differ significantly at $P \leq 0.05$ level.

\section{Discussion}

Effect of water stress and AM fungi on growth performance of pea plant

The present investigation was conducted to determine the effect of arbuscular mycorrhizal fungi and water stress on growth of pea plant. The data was prepared and collected at the time interval of 15 days. The treatment of water stress was given to the plants after four, eight and twelve days.

Effect of water stress and AM fungi on the shoot and root length and the number of leaves of pea plant

The mycorrhizal plants have shown more shoot and root length as compared to the control plants. The height of shoot and root was significantly decreased with the increase in drought stress. Mycorrhizal plants with low water stress showed enhanced shoot and root length than high water stress. The results were in agreement with Auge and Moore (2005) and Galvan et al., (2008). Kothari et al., (1991) observed that rate of water uptake per unit root length and per unit tissue by AM were twice that of control plants.

The mycorrhizal plants have shown more number of leaves than control plants during drought stress. The number of leaves significantly reduced with the increase in drought stress. The leaves produced by the control plants were comparatively smaller than those of mycorrhizal plants. The results were significant at $\mathrm{P} \leq 0.05$ level.

\section{Effect of water stress and AM fungi on the dry weight of root and shoot of pea plant}

The dry weight of root and shoot was recorded in control and mycorrhizal plants after giving drought stress. The water stress was given at 4, 8 and 12 days interval in mycorrhizal as well as control plants. The dry weight of root and shoot of both control and mycorrhizal plants decreased with the increase in water stress. Mycorrhizal plants showed more dry weight of shoot and root as compared to control plants. The results were significant at $P \leq 0.05$. Plants inoculated with AM fungi produce more dry weight than the control plants. These results have also been reported by Wu and Xia $(2004,2006)$ and Wu et al., (2008). 
Effect of water stress and AM fungi on the fresh weight of root and shoot of pea plant

The fresh weight of both control and mycorrhizal plants has been decreased with the increase in water stress interval. It has been found that the fresh weight of root and shoot was observed higher in mycorrhizal plants as compared to those of control plants. Fresh weight of shoot and root was significantly high in those plants which were watered at the interval of 4 days. However, it was least in the plants watered at the interval of 12 days. The results were in agreement with Patale and Shinde (2012). The results were significant at $\mathrm{P} \leq 0.05$ level.

\section{Conclusions}

Effect of water stress and AM fungi on growth performance of pea plant

Water stress treatment was given to the plants after 30 days at the interval four, eight and twelve days. The data was recorded at the interval of 15 days to determine the effect of arbuscular mycorrhizal fungi and water stress on growth of pea plant.

Effect of water stress and AM fungi on the dry weight of root and shoot of pea plant.

The water stress was given at the interval of 4, 8 and 12 days in mycorrhizal as well as control plants and the dry weight of root and shoot was recorded in control and mycorrhizal plants. The dry weight of root and shoot of both control and mycorrhizal plants decreased with the increase in water stress. Mycorrhizal plants showed more dry weight of shoot and root as compared to control plants. Mycorrhizal plants with minimum water stress interval showed enhanced shoot and root length than maximum water stress interval.

Effect of water stress and AM fungi on the fresh weight of root and shoot of pea plant.

The fresh weight of both control and mycorrhizal plants has been decreased with the increase in water stress interval. Fresh weight of shoot and root was significantly high in those plants which were watered at the interval of 4 days than those which were watered at 12 days interval. It has been found that the fresh weight of root and shoot was observed higher in mycorrhizal plants as compared to those of control plants.

Effect of water stress and AM fungi on the shoot and root length and the number of leaves of pea plant.

The mycorrhizal pea plants were taller than non mycorrhizal plants during water stress. The height of shoot and root was significantly decreased with the increase in drought stress. Mycorrhizal plants with low water stress showed enhanced shoot and root length than high water stress. The mycorrhizal plants have shown more number of leaves than control plants during drought stress. There was a significant decrease in the number of leaves with the increase in drought stress.

\section{References}

Aroca, R., Porcel,R. and Ruiz-Lozano, J.M. 2007. How does arbuscular mycorrhizal symbiosis regulate root hydraulic properties and plasma membrane aquaporins in Phaseolus vulgaris under drought, cold or salinity stresses? New Phytologist, 173: 808-816.

Auge, R.M. and Moore, J.L. 2005. Arbuscular mycorrhizal symbiosis and plant drought resistance. In: Mehrotra VS (ed) Mycorrhiza: role and applications. Allied Publishers Limited, New Delhi, pp 13. 
Auge, R.M., Kubikova, E. and J.L. Moore 2001. Foliar dehydration tolerance of mycorrhizal cowpea, soyabean and bush bean. New Phytologist,151(2):535-541.

Barea, J.M., M.J. Pozo, R. Azcon and C. Azcon-Aguilar 2005. Microbial cooperation in the rhizosphere. J. Exp.Bot., 56:1761-1778.

De la Pena, E., Rodriguez, E.S., van der Putten, W.H., Freitas, H. and Moens, M. 2006. Mechanism of control of root feeding nematodes by mycorrhizal fungi in the dune grass Ammophila arenaria. New Phytologist, 169:829-840.

Galvan, G.A.,K. Burger-Meijer, Th.W. Kuyper, C. Kik and O.E. Scholten. 2008. Possibilities fir breeding to improve responsiveness to arbuscular mycorrhizal fungi in onion. $16^{\text {th }}$ IFOAM Organic World Congress.

Gange, A.C. 2001. Species-specific responses of a root and shoot feeding insect to arbuscular mycorrhizal colonisation of its host plant. New Phytol, 150: 611-618.

Heikham, E. Kapoor, R. and Giri, B. 2009. Arbuscular mycorrhizal fungi in alleviation of salt stress: a review. Annals of Botany, 104(7): 1263-1280.

Hildebrandt, U., Kaldrof, M. and Bothe, H. 1999. The zinc violet and its colonisation by arbuscular mycorrhizal fungi. Journal of plant Physiology, 154: 709-717.

Koide, R.T. and Kabir, Z. 2000. Extraradical hyphae of the mycorrhizal fungus Glomus intraradices can hydrolyse organic phosphate. New Phytol, 148:511-517.

Koide, R.T. and Mosse, B. 2004. A history of research on arbuscular mycorrhiza. Mycorrhiza, 14: 145-163.

Kothari, S.K., H. Marschnere and V. Romheld 1991. Effect of arbuscular mycorrhizal fungus and rhizosphere microorganisms on manganese reduction in the rhizosphere and manganese concentration in maize (Zea mays L.). New Phytol, 117:649-655.

Michelson, A. and Rosendahl, S. 1990. The effect of VA mycorrhizal fungi, phosphorus and drought stress on the growth of Acacia nilotica and Leucaena leucocephala seedlings. Plant and soil, 124: 7-13.

Patale, S. W. and B. P. Shinde 2012. Studies on AM fungi of Bt cotton (Gossypium hirsutum, L.). Ph.D. Thesis, University of Pune.

Smith, F.A., Grace, E.J. and Smith, S.E. 2009. More than a carbon economy: nutrient trade and ecological sustainability in facultative arbuscular mycorrhizal symbiosis. New phytol, 182: 347-358.

Vigo, C., Norman, J.R. and Hooker, J.E. 2000. Biocontrol of pathogen Phytophthora parasitica by arbuscular mycorrhizal fungi is a consequence of effects on infection loci. Plant Pathology,49: 509-514.

Wu, Q.S. and R. X. Xia 2006. Arbuscular mycorrhizal fungi influence growth, osmotic adjustment and photosynthesis of citrus under well-watered and water stress conditions. J. Plant. Physiol, 163: 417-425.

Wu, Q.S. and R.X. Xia. 2004. Effects of arbuscular mycorrhizal fungi on growth and osmotic adjustment matter content of trifoliate orange seedlings under water stress. J. Plant Physiol. Mol. Biol., 30: 583-588. 
Wu, Q.S., R.X. Xia and Y.N. Zou 2008. Improved soil structure and citrus growth after inoculation with arbuscular mycorrhizal fungi under drought stress. Europ. J. of Soil Biol., 44:122-128. 